\title{
Espaços Públicos, Coexistência Social e Civilidade Contributos para uma Reflexão sobre os Espaços Públicos Urbanos ${ }^{l}$
}

Alexandra Castro*

\begin{abstract}
$\mathrm{R}$ das práticas sociais que neles se inscrevem implicaram uma renovação das abordagens aos espaços públicos e um alargamento do debate sobre o seu papel integrador. Este enfoque na função de edificar e reforçar os laços sociais dos espaços públicos, ganha pertinência quando se assiste a um duplo processo na extensão da metropolização caracterizado, simultaneamente, por uma recuperação e uma redução das relações comunitárias. Partindo-se de uma análise dos fenómenos presentes na coexistência socioespacial, procurou-se compreender alguns dos aspectos que tendem para o esvaziamento daquela função dos espaços públicos mais tradicionais e para emergência de novos espaços. Por fim, apresentam-se alguns contributos para a redefinição da urbanidade à luz das novas realidades socioespaciais presentes nos espaços públicos.
\end{abstract}

Palavras-Chave: espaços públicos; civilidade; sociabilidade; coexistência socioespacial; urbanidade.

\section{Introdução}

A teorização do conceito de espaço público é bastante recente no domínio sociológico, nomeadamente no campo da sociologia urbana, abarcando uma multiplicidade de sentidos, fruto da complexidade que o caracteriza. A sua utilização banalizou-se, tornando-se, ainda, mais ambíguo o seu significado, pelo que a abordagem ao conceito nos coloca, desde logo, perante a opção da sua designação no plural ou no singular ${ }^{2} \mathrm{e}$, se a expressão "espaço do público" não traduziria melhor uma abordagem sociológica das questões mais actuais que se colocam a lugares com especificidades tão particulares e irredutíveis a outros espaços. Conscientes da polissemia do conceito e de que a sua formalização numa única categoria reduz a sua riqueza conceptual, este artigo procura contribuir para a reflexão dos espaços públicos na sua dimensão física, enquanto quadro espacial onde se desenrolam as interacções sociais, mas também na sua vertente simbólica, no sentido de dar conta das modalidades e conteúdos destas mesmas interacções.
Compreender como no final do século Xx se assiste, por um lado, a um retorno em força dos espaços públicos como elementos centrais dos projectos urbanos e, por outro lado, se descobre que o espaço público gerando dinâmicas quotidianas essenciais pode ser um instrumento importante e profícuo de coesão social e material da cidade passou por reconhecer que o esquecimento da sua dimensão pública podia estar na origem da crise do laço social e da crise de cidadania que hoje se conhece.

Mais do que uma análise urbanística dos espaços públicos, enquanto elementos estruturadores da forma urbana, e independentemente da sua natureza jurídica e das formas de gestão que são desenvolvidas, este artigo procura debater o papel integrador dos espaços públicos urbanos, ou seja, a sua função de fundar e consolidar os laços sociais, como condição fundamental da qualidade de vida urbana. No fundo, trata-se de discutir um dos vectores da "condição social e culturalmente pública da cidade" (Matias Ferreira, 2000).

Com aquela dimensão pública não se quer remeter o problema, unicamente, para a natureza jurídica dos espaços, trata-se, sim, como refere Matias Ferreira, numa releitura de $\mathrm{H}$. Lefebvre, da

\footnotetext{
* Socióloga. Investigadora do Centro de Estudos Territoriais. Contacto: alexandra.i.castro@seg-social.pt.

1 Este texto foi produzido no quadro de uma investigaçāo em curso no Centro de Estudos Territoriais/ISCTE, intitulada "Património Urbano, Espaço Público e Protagonismo das Cidades. As Metrópoles de Lisboa e Porto no dealbar do século XXI". Esta pesquisa é coordenada por Vítor Matias Ferreira e financiada pela Fundaçāo para a Ciência e Tecnologia.

2 Para um aprofundamento desta distinção cf. Matias Ferreira, 2000 e 2001.
} 
dimensão cultural do urbano, ou seja, “(...) de uma reivindicação política e cultural em relação à vida urbana, entendida, sobretudo, ao nível dos processos de sociabilidade urbana e de fruição plena da cidade (...) o que remete para os processos de apropriação pública do espaço urbano" (Matias Ferreira, 2000: 15).

A actualidade deste debate justifica-se pelo facto da problemática dos espaços públicos ter, hoje, de ser equacionada à luz da transformação do estatuto dos diferentes espaços urbanos e metropolitanos (nomeadamente a que remete para a redefinição da dicotomia público/privado) e das práticas urbanas a eles associados (concretamente os modelos de civilidade e de sociabilidade).

\section{A Reconstrução da Dicotomia Público / Privado}

São vários os autores que reconhecem que a abordagem do espaço público não se esgota numa análise da sua natureza jurídica (cf. Capron,1998; Toussaint et al., 2001, entre outros). A passagem da noção de espaço público a "espaço do público" coloca a questão do estatuto do espaço comum. O espaço público é uma determinação político-jurídica, mas também um produto do uso social, ou seja, existem espaços públicos inacessíveis ou proibidos e outros, que não são juridicamente públicos, mas têm um uso colectivo intenso. A noção de público não é, pois, uma qualidade intrínseca a um espaço, mas sim uma construção social e política que resulta da combinação de vários factores, nomeadamente dos usos aí confinados; do sentido que é atribuído por um determinado grupo social; da acessibilidade; da tensão entre o estrangeiro/anónimo e o reconhecimento/reencontro; da dialéctica entre proximidade e distância física e social. Mais adiante teremos oportunidade de desenvolver estes factores, mas parece ainda relevante debruçar-nos sobre a utilização desta noção de público, pelas questões que ela encerra.

Rémy e Voyé referem que foi a sociedade contemporânea que deu uma plausibilidade particular à dicotomia público/privado, nomeadamente pela importância que assume "a propriedade privada dos bens e a dos direitos dos cidadãos como quadro de referência juridicamente formulado e apoiado pela autoridade política" (Rémy e Voyé, 1981: 107). No entanto, deve ter-se presente que esta dicotomia tem, fundamentalmente, uma função cultural de distribuição de comportamentos e usos legítimos. Miles lança, contudo, um alerta para o facto desta categorização binária tender a ignorar os espaços transicionais ou semipúblicos (as varandas e os pátios populares são alguns dos exemplo possíveis), colocando problemas ao planeamento urbano, nomeadamente quando se marginaliza o domínio do doméstico, pois em tais locais as pessoas intervêm directamente nos seus próprios espaços, condicionando a formação de padrões de socialização (Miles, 2000: 101).

Mas para aqueles autores a oposição público/ /privado recobre, genericamente, a oposição exterior/interior, distinguindo-se o que é da ordem da esfera privada (família) e o que é visível por todos. Referem, assim, que o uso corrente do termo privado está associado, por um lado, a um domínio de actividade onde não pode interferir um poder exterior e, por outro, a um espaço cujo acesso é controlado, pelo indivíduo ou grupo, a actividades sem visibilidade social, ou seja, sem que os outros tenham o direito de ser informados. $O$ termo público definir-se-ia, então, pelo inverso dos critérios associados à noção de privado, ou seja, reenvia à noção de acessibilidade totalmente livre: possibilidade de a ele aceder em qualquer momento, por qualquer pessoa, para desenvolver actividades não explicitamente determinadas. Trata-se de um espaço em que o homem, como cidadão ou hospedeiro, tem uma liberdade total de circulação e onde é possível a interacção livre e não controlada entre indivíduos supostamente autónomos (Rémy e Voyé, 1981: 91-94).

\section{Dimensões Centrais do Espaço Público}

Uma definição alargada de espaço público ${ }^{3}$ coloca, assim, como princípio a sua acessibilidade

\footnotetext{
Como já referimos noutros momentos (cf. Matias Ferreira e Castro, 2000; Castro et al. 2001), a construção do conceito de espaço público em sociologia urbana foi mais controversa do que noutras áreas disciplinares por se ter privilegiado a sua associação com a análise dos espaços residenciais e a consequente diversidade de culturas urbanas e modos de apropriação do espaço aí presentes. O acento dado a esta associação fez emergir uma série de estudos que viam o espaço público apenas como um prolongamento do espaço privado do habitat, ou ainda como um espaço colectivo apropriado por uma comunidade que o bairro deveria traduzir, através da sua escala, da sua estrutura, da sua forma e da própria vizinhança. Recentemente, a conceptualização da noção de espaço público tem caminhado, a par das transformações urbanas e sociais, daquela concepção mais restrita para uma noção mais abrangente. Isaac Joseph $(1991,1998)$ é um dos autores que tem concentrado a sua atenção numa visão mais alargada de espaço público que vai desde a rua, até ao centro comercial, passando por estações de metro ou de comboio ou mesmo por parques de estacionamento.
} 
a todos, o lugar onde qualquer indivíduo pode circular livremente, em contraponto ao espaço privado, cujo acesso é controlado e reservado a um público específico. O critério de acessibilidade repousa sobre a ideia implícita de que é a livre circulação do corpo no espaço que o torna público e que estes espaços acessíveis pressupõem “(...) encontros socialmente organizados por rituais de exposição ou de inibição que pouco se relacionam com a convivialidade inerente à vida de bairro e das relações de vizinhança" (Joseph, 1998: 52). Tratam-se de espaços públicos específicos que pressupõem diferentes escalas de envolvimento dos actores entre si e com o próprio espaço.

Como refere Philippe Graff, estamos perante um "espaço de cidadania" e um espaço de exercício do "direito à cidade", cuja frequência reclama apenas o estatuto de cidadão. Nesta óptica, a ideia de espaço público destaca a afirmação de um direito público, de exercício da cidadania, cuja acessibilidade e visibilidade constituem o próprio pressuposto inerente à sua fruição (Graff, 1996: 153). Não parece demais insistir que perante os desafios que hoje se colocam na abordagem dos espaços é importante relembrar que "o espaço público é um desafio global à política urbana: um desafio urbanístico, político e cultural, referido a toda a cidade" (Borja, 2000: 84). Borja alerta, assim, para o facto, do espaço público, independentemente da escala do projecto urbano, dever organizar um território capaz de suportar diferentes usos e funções e não se ignorar que ele é também espaço de expressão colectiva, da vida comunitária, do encontro, ou seja, uma questão de vontade política e de respeito pelos direitos do cidadão ${ }^{4}$. É, ainda, um desafio cultural, na medida em que é um dos melhores indicadores dos valores urbanos predominantes.

Verifica-se, pois, ao longo desta exposição a existência de duas dimensões presentes no conceito de espaços públicos. Por um lado tratam-se de "espaços do visível", regulados por um "direito de olhar" e, por outro, de espaços acessíveis, ordenados por um "direito de visita". No seguimento deste raciocínio, Hervé Le Bras (1997) refere que "o habitante das cidades tornou-se num tipo de convidado no espaço público urbano", onde deve comportar-se de maneira cada vez mais codificada. Para este autor a questão já não reside tanto na forma como a hospitalidade permite aos indivíduos reconhecerem-se mas, sobretudo, na maneira como a hospitalidade urbana ${ }^{5}$, traduzida em "gigantescos espaços de recepção", mantém à distância e domina cada vez mais um conjunto de pessoas sem pertenças definidas.

É, assim, que retendo uma daquelas dimensões se deve ter presente que uma questão prévia ao desenvolvimento diferenciado de formas de estar e "viver" nos espaços públicos diz respeito às formas de acessibilidade aos espaços públicos urbanos. Esta é uma questão largamente desenvolvida por I. Joseph (1998), sobretudo, por representar um valor fundamental da urbanidade, já que as sociedades urbanas sempre foram avaliadas em função da sua oferta de mobilidade, tanto espacial como social. Segundo este autor, determinados espaços são acessíveis não só pelas suas qualidades arquitectónicas, mas também pela sua capacidade em articular visibilidades e enunciados, ou seja, pela sua capacidade em oferecer deslocações, caminhos e movimentos, mas também "paragens" disponíveis e perceptíveis pelos seus utilizadores.

No fundo, muitos dos espaços eleitos por esta noção de espaço público remetem para o conceito proposto por Marc Auge de "não-lugares", ou seja, espaços marcados por relações transitórias e anónimas, espaços promovidos à individualidade solitária (Augé, 1994). Apesar de neste tipo de espaços se estar, essencialmente, perante "interacções não-focalizadas", não se deve descurar o facto destas apresentarem formas específicas de troca e coexistência. François Ascher acusa mesmo Marc Augé de uma certa miopia nesta concepção de determinados espaços públicos pelas suas repercussões negativas quando a noção é recuperada por arquitectos e urbanistas responsáveis pela concepção de espaços públicos (Ascher, 1998: 174). Mas aquela forma de olhar para determinados espaços públicos não deixa de

\footnotetext{
${ }^{4}$ Sitte foi um dos autores que se preocupou em compreender não apenas as regras de produção dos espaços públicos, mas também os seus múltiplos significados, próprios da vida social urbana, nomeadamente a sua função de comunicação directa entre pessoas, mesmo que este jogo social fosse feito de uma grande teatralidade, como eram as entradas e saídas de espectáculos ou o passeio público da cidade novecentista. É neste contexto que se organizavam, em Paris, os cortejos entre praças: os cortejos Norte-Sul eram os da celebração, sendo o Panthéon lugar do ajuntamento; os cortejos Este-Oeste eram os de contestação e os cortejos no eixo dos Champs-Elysées celebravam os feitos do regime (Ozouf, citado por Rémy e Voyé, 1981: 105).

5 Para um aprofundamento deste conceito ver Gotman (2001).
} 
ser relevante quando estes parecem não ter ou estar a perder a sua função de edificar e reforçar os laços sociais. Vejamos de seguida, alguns dos factores que têm contribuído para este enfraquecimento do papel integrador dos espaços públicos. mentado (zona de habitação, lazer, trabalho...) e a sua forma rígida (tradição do "modernismo clássico").

Ainda segundo este autor, foi a partir dos anos 80 que os profissionais do espaço mudaram a sua

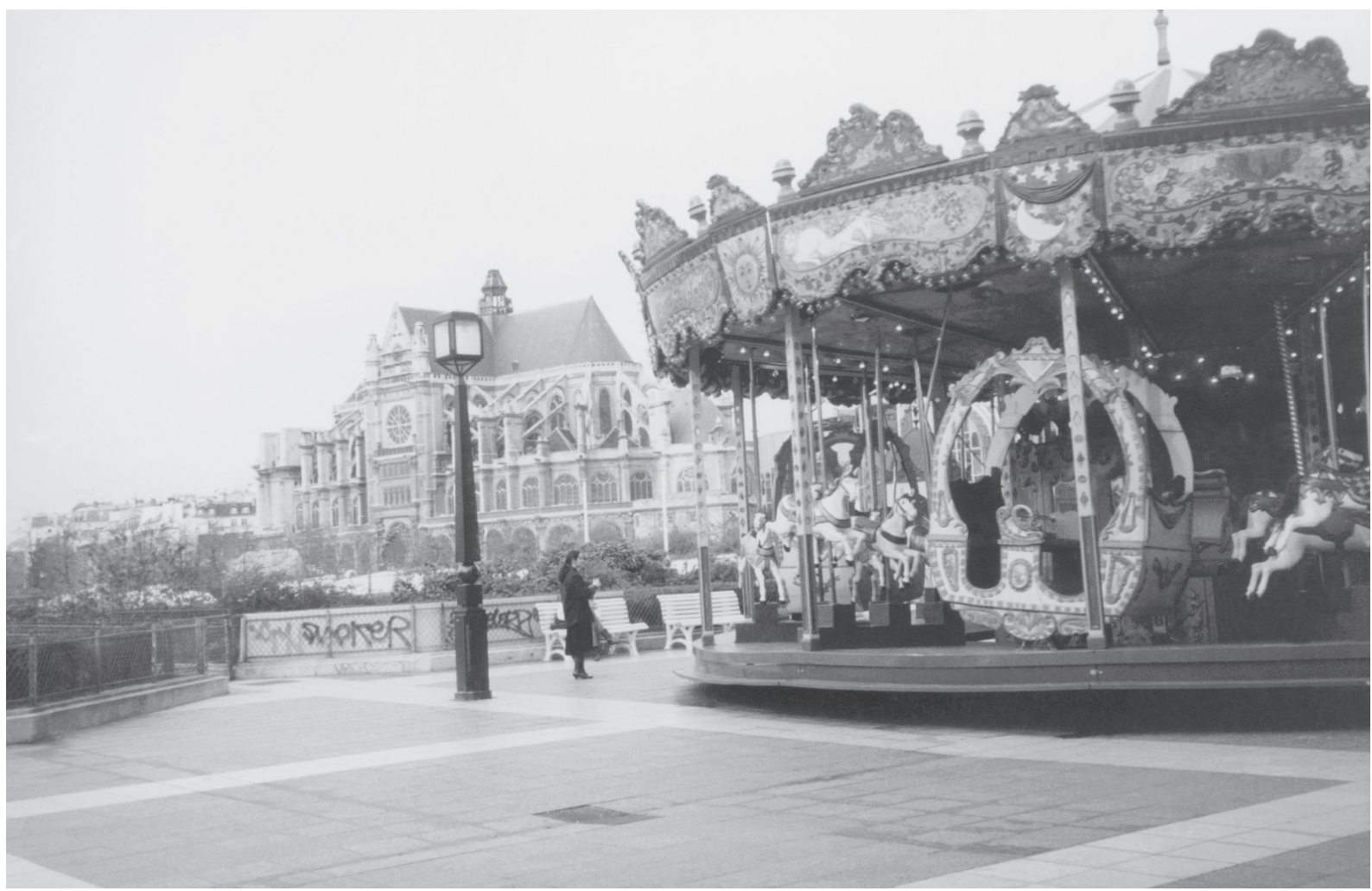

Foto de Alexandra Castro, Chatelêt, Paris.

\section{Da "Crise dos Espaços Públicos" à Agorafobia}

A importância e o desafio que os espaços públicos hoje colocam não devem fazer esquecer que no início do século Xx, o urbanismo operacional conduziu a um abandono do espaço público, pois predominava a lógica da integração económico-funcional. A forma urbana não era gerada a partir da produção de uma estrutura de espaço público, mas resultava de uma ocupação funcionalista do solo sob a forma de zonas especializadas e de figuras em rede. As intervenções urbanísticas limitavam-se a prever o esgotamento do fluxo de peões no espaço deixado vago pelo automóvel. Marcus Zepf (2001a: 173) constata que, no final dos anos 60, os espaços urbanos ofereciam pouca qualidade para serem lugares de sociabilidade urbana, sobretudo, por três ordens de razões: a sua monofuncionalidade (circulação, estacionamento...); o seu uso frag- lógica de discurso e de acção. Os objectivos emergentes passavam por promover o marketing das cidades numa lógica de competitividade urbana e, desta forma, estabelecer a qualidade de vida e fazer surgir a sociabilidade sustentável (Zepf, 2001: 173). Na mesma linha de raciocínio, Pedro Brandão identifica vários factores que tendem para a valorização do espaço público e o elevam à categoria de "nova cultura de cidade". Tendo ficado para trás a fase em que a prioridade da intervenção sobre os espaços das cidades tinha de ser dada às necessidades básicas, o espaço público tende a assumir-se cada vez mais como um elemento de competitividade entre as cidades, já que se elevou o padrão cultural de expectativas e os termos comparativos da qualidade de vida (Brandão, 2000: 55-56).

Como já salientámos noutros momentos, as tendências mais recentes parecem, pois, não ser a de edificar e dotar os territórios urbanos de maior 
objectividade, mas torná-los mais significativos: diversamente tematizados e projectados à imagem de uma sociedade mais complexa e de actividades e funções mais diversificadas. Os processos de transformação da cidade existente, desencadeados, nomeadamente, pela reconversão das áreas devolutas, deixam de se destinar apenas aos habitantes de um determinado bairro ou cidade, participando, igualmente, num projecto mais alargado de promoção urbana e de novos estilos de vida, onde se evidencia a cidade como objecto estético, lugar de memória e de dimensão internacional. Tenta-se criar, deste modo, um núcleo forte, dinâmico e visualmente atraente, para captar novas actividades e populações. Pode afirmar-se que as cidades e o modo de vida urbano parecem estar outra vez na "moda", fenómeno este visível através de uma convergência de estratégias económicas, políticas e sociais que colocam o acento no investimento de uma nova urbanidade (Matias Ferreira et al., 1997: 83-84).

De facto, a transposição do conceito de espaço público do domínio da filosofia política para o campo do urbanismo está intimamente interligada com o movimento de retorno à cidade e com o esvaziamento da substância política do conceito.
É, pois, num momento em que a comunidade é violentada, discutida, fracturada que aparece o espaço público como conceito operatório do planeamento urbano e como um instrumento político para enquadrar e reforçar o laço social. Neste sentido, Toussaint e Zimmermann referem que o espaço público constitui o lugar de confronto político pelo qual se define e institui a sociedade. Este confronto não se limita apenas aos "acontecimentos" (manifestações, desfiles...), mas estende-se também ao quotidiano quando se põe à prova o comportamento de uns em relação aos outros. É a partir destas fricções que os grupos sociais e os indivíduos aprovam valores e normas que os defendem ou tentam impô-los como sendo universais (Toussaint e Zimmermann, 2001: 266). Na mesma linha de pensamento, Quéré refere que "a noção de espaço público comporta duas ideias essenciais: uma esfera pública de livre expressão, de comunicação e de discussão, constituindo esta esfera uma instância mediadora entre a sociedade civil e o Estado, entre o cidadão e o poder político-administrativo; uma cena pública, ou seja, uma cena de aparição, onde acedem à visibilidade pública tanto actores como acontecimentos e problemas sociais" (Quéré, 1992).

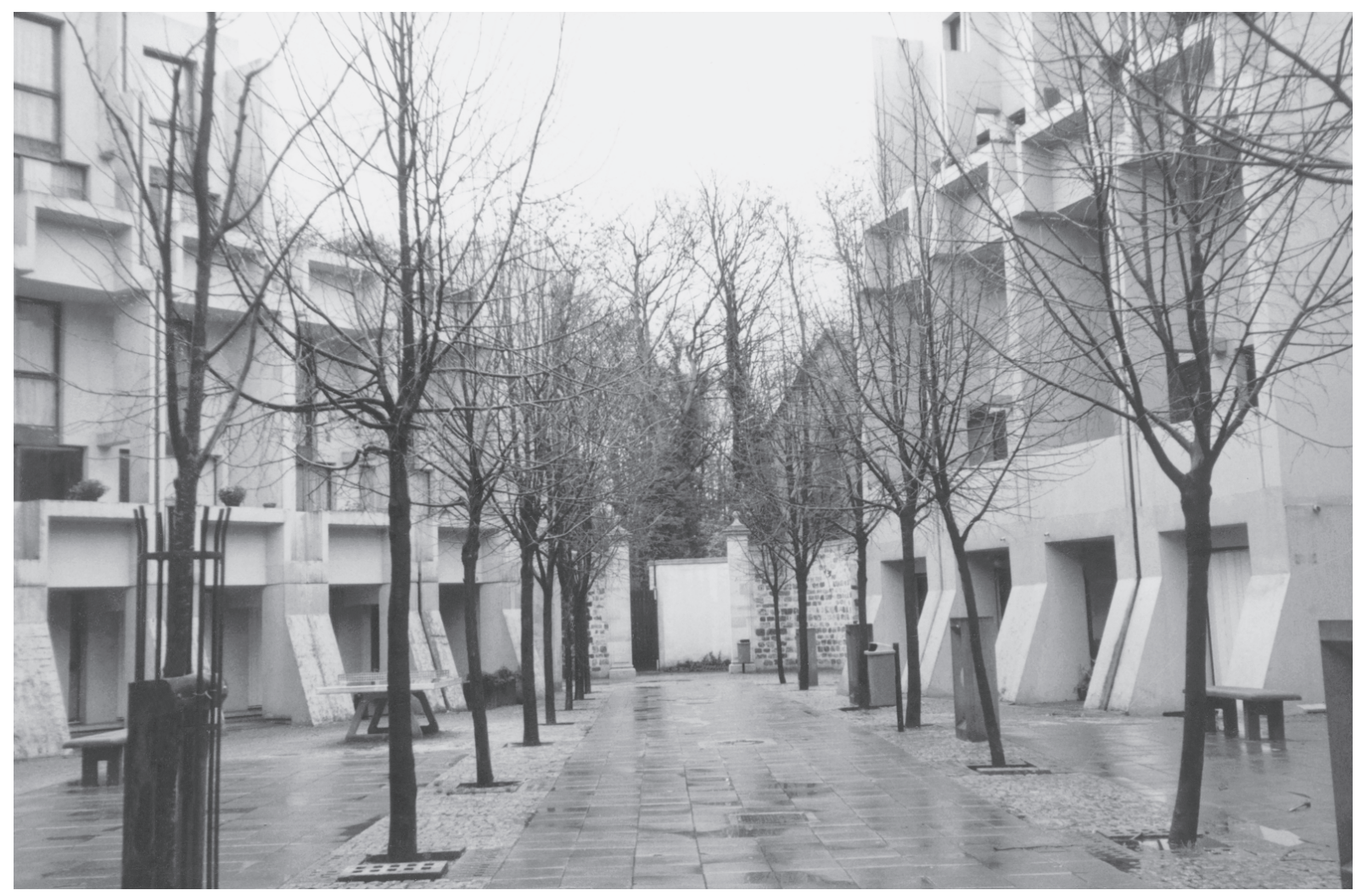

Foto de Alexandra Castro, Saint-Denis, Paris. 
Quando R. Sennet (1979) nos fala da "teatrealidade do jogo social" quer dizer que não existe sociabilidade sem teatrealidade e o declínio do homem público e do espaço público decorrem directamente do desaparecimento dos papéis e dos rituais sociais. Este desaparecimento está condicionado pela nova ideologia da transparência e da autenticidade que impõem novas normas de comportamento em público que passam por exibir a personalidade e a vida privada, característica de comportamentos egocêntricos e narcisistas. Para o autor esta confusão é fatal ao espaço público, e no fundo trata-se da consequência da "tirania da intimidade" que se exerce hoje nas relações sociais. Mais adiante veremos como esta noção foi recuperada por Levy (1997) para caracterizar determinado tipo de espaço público.

Também Levy concorda que se assiste efectivamente a uma crise do espaço público: a cena pública mediática tende a substituir cada vez mais a cena pública urbana e a simbólica a transformar-se em espectáculo (Levy, 1996: 65). Mas é também o quadro físico e as propriedades do espaço público que podem, igualmente, condicionar o desenvolvimento de sociabilidades. É neste sentido que Levy (1997) introduz a noção de "espaço público incivil" para caracterizar os espaços que apresentam um certo número de carências: falta de serviços públicos e equipamentos; tratamento estético inexistente ou medíocre; não reconhecimento das especificidades locais; acessibilidade nula ou reduzida ${ }^{6}$. Como veremos mais adiante não são tanto as condições materiais necessárias ao bom funcionamento dos espaços públicos que mais preocupam este autor, mas, sobretudo, as condições de sociabilidade que organizam a co-presença dos indivíduos.

Verifica-se, pois, que tendo sido superados os factores mais negativos associados aos espaços públicos urbanos, surgiram outros relacionados com uma "crise dos públicos", manifestada, nomeadamente, pela agorafobia. Como refere Indovina (2002), no texto publicado neste número, está-se perante um circulo vicioso: o vazio social do espaço público é determinado pela insegurança, mas o enfraquecimento do papel social e de socialização da cidade tende a incrementar a este sentimento, pois dá margem ao desenvolvimento de compor- tamentos que geram insegurança. Assiste-se, então, a uma fragmentação do espaço público, já que a agorafobia tende a identificar a segurança como privatização (Borja, 2000). Um exemplo é a proliferação de "comunidades fortificadas", sobretudo nas cidades americanas, que respondem à procura de determinadas camadas da população que tendem a desenvolver modos de vida no interior de um espaço com acesso condicionado e de visibilidade selectiva.

É neste sentido que alguns autores têm chamado a atenção para o duplo processo presente na extensão da metropolização: por um lado, o crescimento do individualismo e a promoção da diferença como estrutura fundadora da ordem social e, por outro lado, uma procura permanente de espaços públicos como lugares de afirmação social ou de simples compensação. O mesmo é dizer que a "metapolização" tende a produzir, simultaneamente, uma recuperação e uma redução das relações comunitárias (cf. Volle, 1996; Ascher, 1998). É sobre este jogo paradoxal e pela importância analítica de se distinguirem os vários tipos de espaços que se irá centrar de seguida a nossa atenção.

\section{Civilidade, Sociabilidade e Coexistência Socioespacial}

Partindo-se da constatação que o mesmo espaço pode acolher simultânea e sucessivamente utilizadores diferentes, fica, pois, por saber, face à segmentação dos usos do espaço público, como definir o tipo e a qualidade de um espaço que acolhe actividades e públicos diversos, tornando possível a sua coexistência.

As pesquisas que se têm centrado sobre a coexistência de grupos sociais muito diversificados num mesmo espaço, constatam a dificuldade de gestão das relações sociais entre grupos. Para Pinçon (1981) este fenómeno relaciona-se, sobretudo, com o facto da proximidade física não corresponder a uma proximidade social e de, na ausência de um grupo dominante, se assistir ao confronto de práticas e valores diversificados consoante os grupos que procuram impor-se. Muitos conflitos estão na origem de incompreensões alimentadas por concepções e práticas diferenciais

\footnotetext{
${ }^{6}$ Brandão identifica também alguns pontos fracos que tendem a permanecer nos espaços públicos: má qualidade dos espaços limites do espaço público; degradação dos existentes; impacto do automóvel: barreiras, aumento das desigualdades na acessibilidade; falta de identificação com o lugar; hábitos de socialização pobres; pouca vivência exterior; ruído visual da publicidade (Brandão, 2000: 56).
} 
do espaço público e do espaço privado, por comportamentos julgados naturais por uns e reprovados por outros.

Segundo Mayol os conflitos podem ser minimizados, ao nível dos comportamentos, por aquilo a que o autor chamou de "conveniência", ou seja, "(...) um compromisso, através do qual cada um, renunciando à anarquia dos impulsos individuais, fornece contributos à vida colectiva, no sentido de retirar benefícios simbólicos necessariamente diferenciados no tempo" (Mayol, 1980: 15).

É através deste conceito, e de acordo com o mesmo autor, que é possível analisar dois aspectos fundamentais da organização da vida quotidiana nos espaços exteriores: o dos "comportamentos" visíveis nos espaços públicos, através da representação do corpo, do ritmo das caminhadas e da eleição de espaços preferenciais; e o dos "benefícios simbólicos adquiridos" que se encontram enraizados na tradição cultural do indivíduo, manifestando-se nas formas como este se apropria do espaço público e através dos seus discursos, impregnados de sentido, sobre as suas deslocações (Mayol, 1980: 15).

Uma apropriação forte dos espaços públicos não tem necessariamente de ser negativa. No entanto, o espaço público pode tornar-se, para certas categorias da população e em certos momentos, um espaço de poder quando determinados grupos põem em prática estratégias de ocupação e comportamentos que visam a exclusividade. Uma investigação recentemente terminada centrou-se na análise das representações existentes sobre a comunidade cigana em contextos de co-presença com não ciganos e permitiu concluir que as singularidades dos vários grupos sociais tomam forma no espaço, concretizando-se as heterogeneidades em diversos modos de apropriação do espaço e eventualmente conflituais. De facto, o confronto cultural (materializado em diferentes modos de usar e estar no espaço) constituiu um momento fundamental na percepção dos limites das identidades sociais em co-presença. Nesse sentido, o confronto com os ciganos nos espaços estudados, traduz-se na constatação de dois aspectos fundamentais: a sua extrema visibilidade nos espaços públicos e o seu auto-centramento na apropriação do espaço. As representações sobre a apropriação do espaço por parte da comunidade cigana organizam-se em torno da ideia de trans- gressão, pelo facto dos ciganos ignorarem todas as regras de apropriação dos espaços públicos (cf. Castro et al., 2001).

Embora o espaço público possa ser um modo de aprendizagem de outras formas de sociabilidade e da própria diferença, não implica que o confronto com o outro produza necessariamente um sentimento de conivência e reconhecimento. Tornando as diferenças palpáveis, o confronto pode conduzir a uma exacerbação dos preconceitos e a tensões conflituais. Para Ascher parece, pois, necessário, na actual configuração "metapolitana", a existência de espaços específicos - espaços comunitários do "entre nós" - para determinadas comunidades desenvolverem as suas práticas, isto no pressuposto de que "se quer evitar que não sejam reprimidas ou que, ao contrário, não constituam factores de exclusão ou de conflitos"(Ascher, 1998: 177). Esta exigência parece resultar de um certo desconhecimento do modo de funcionamento dos grupos e de uma grande dificuldade em se distinguir no comportamento do outro o que é efectivamente da ordem da agressão ou da intimidação. É perante esta "incapacidade" de se interpretarem as intenções dos outros que se gera o sentimento de insegurança e algumas das dificuldades de coexistência de grupos sociais muito heterogéneos.

Verifica-se, assim, que a mistura social não é suficiente para fazer com que um lugar contribua para o reforço do laço social. É necessário perceber o que dá sentido à mistura, a maneira como é vivida, percebida e julgada e ter presente que "a miscigenação é um dos factores que favorece a emergência da urbanidade" (Bassand et al., 2001: 64). Foram estas preocupações que levaram alguns autores a sistematizar diferentes modalidades de espaços públicos.

\section{Contributos para um Exercício de Tipificação dos Espaços Públicos}

A relação com o espaço público e com os outros indivíduos parece estar muito condicionada pelo estatuto de quem o usa - habitante, cidadão comum ou comunidades - , pelo tipo de espaço público que enquadra as interacções sociais e pelas formas de sociabilidade que aí são desenvolvidas. Levy (1997), uma equipa coordenada por Bassand (2001) e Pipard e Grané (2001) foram alguns dos autores que chamaram a atenção para as espe- 
cificidades de determinados espaços públicos. De seguida apresentam-se as propostas destes autores para a tipificação destes espaços, sendo, no entanto, de salientar que se tratam de tipologias de natureza muito distinta, pois procuram responder a propósitos igualmente diferentes. As duas primeiras referências tratam-se de pesquisas realizadas no âmbito académico, ao passo que a última é uma sistematização de trabalhos realizados como respostas a encomendas de planeamento e avaliação dos espaços públicos.

Levy (1997) guiando-nos numa "exploração" do estado de conhecimentos sobre a natureza, estrutura, funcionamento e finalidade do espaço publico pesquisa os critérios que permitam uma abordagem tipológica, no sentido de pôr em evidência diferentes modos de existência (ou não) do espaço público. A equipa coordenada por Bassand (2001), preocupada com a forma de dar conta da miscigenação presente nos espaços públicos do centro da cidade e partindo da hipótese de que estes espaços são uma das instâncias urbanas que permitem a miscigenação, sendo esta uma condição necessária à emergência da tolerância, do compromisso de coexistência e da urbanidade, procura afinar o conceito de miscigenação, através da comparação de três tipos de espaços públicos. Por fim, Pipard e Grané (2001) centrados nas questões de programação e avaliação dos espaços públicos, desenvolvem metodologias de observação destes espaços, abordam-nos teoricamente, mobilizando os conceitos de apropriação e da percepção e põem em evidência a oposição entre duas modalidades de espaços públicos.

\section{A) A exploração do Conceito de Civilidade à} Luz de Quatro Tipos de Espaços

Lévy considera que existem duas grandes categorias de oposição que parecem estruturar o espaço público e a sociabilidade que o define: uma de tipo societal - "interconhecimento vs anonimato" - que corresponde grosso modo à oposição pequena/grande cidade; outra de carácter mais individual - "transparência vs opacidade" que dá conta das modalidades, dos procedimentos e dos conteúdos das interacções.

O cruzamento destas duas grandes categorias produzem quatro tipos de espaços públicos marcados por sociabilidades particulares, tradutoras de formas diferentes de civilidade. Estas duas categorias não se sobrepõem e não se pode estabelecer uma correspondência directa e imediata entre, por exemplo, sociedade de interconhecimento e transparência das relações. Em ambos os tipos de sociedade o grau de civilidade é, sobretudo, avaliado pelo conteúdo e a forma da troca da comunicação social em público. O tipo de sociedade, apenas interfere como um factor que pode fazer variar a forma de civilidade - fria ou quente.

Lévy embora reconhecendo que está a apresentar uma tipologia grosseira, distingue estas duas grandes formas de civilidade, em função da natureza da cidade, do seu tamanho e grau de desenvolvimento, admitindo, contudo, a possibilidade de se encontrar uma variedade de situações intermédias, sem dúvida mais próximas da realidade, e de poderem coexistir diferentes modos de civilidade no mesmo espaço. Alerta, ainda, para o facto de as denominações encontradas para qualificar e identificar os diferentes tipos de civilidade, não remeterem para juízos de valor, mas foi a forma encontrada para dar conta da natureza das interacções, da sua intensidade, do seu conteúdo e frequência.

Os conceitos de civilidade e sociabilidade são muitas vezes considerados sinónimos, no entanto, o autor considera relevante fazer a sua distinção. Por civilidade Levy entende a "competência simbólica mediadora da comunicação social e reguladora da sociabilidade" (Levy, 1997: 26). Trata-se, no fundo, dos diversos saber-fazer relativos aos comportamentos que modelam as interacções quotidianas em público (normas de conduta, regras de conveniência, formas de cortesia), mas também de um dever-fazer, ou seja, de uma ética que prescreve os comportamentos possíveis e desejáveis e os limites a observar de acordo com o código de civilidade (Levy, 1997: 24). A sociabilidade, por seu lado, provém da prática, e pode ser definida como "uma performance que corresponde a pôr em prática o código de civilidade, é uma actualização da competência pela execução de regras de conduta em determinada situação particular" (Levy, 1997:24).

No sentido de identificar os tipos de espaços públicos que a dicotomia civilidade/sociabilidade produz, o autor vai privilegiar as duas principais esferas de acção à escala urbana para abordar o espaço público: esferas de acção individual-pública 
e colectiva-pública. Estas duas esferas correspondem respectivamente a relações inter-individuais e inter-comunitárias, correspondendo a primeira à esfera da apresentação do sujeito em público e dos múltiplos papéis que ele aí pode assumir e a segunda à esfera das atitudes que as diversas comunidades desenvolvem entre si em público. $\mathrm{O}$ acento que é dado a esta última esfera é justificado pela relevância da questão étnica e o lugar crescente que ocupa na cena pública.

De uma forma esquemática e resumida, apresenta-se de seguida as principais características desta tipologia:

1) À sociedade de anonimato, caracterizada pela opacidade das relações, corresponde o espaço público da grande cidade. Aqui as relações inter-individuais são caracterizadas por uma postura de reserva, de indiferença, mútua estranheza e repulsão partilhada. Os comportamentos são estruturados por mediações simbólicas impessoais, verificando-se uma exclusão da comunicação social dos dados biográficos dos indivíduos. Nas relações intercomunitárias verifica-se uma abertura entre grupos; uma aceitação da competição e das normas que a regulam; o reconhecimento de valores comuns a partilhar e a dissolução das especificidades dos grupos. Corresponde, no fundo, à ideologia e à prática da assimilação, onde a sobrevivência de particularismos é considerada um arcaísmo

2) À sociedade de interconhecimento caracterizada pela opacidade das relações corresponde o espaço público da pequena cidade e de certos bairros populares das grandes cidades, ou seja, um meio onde os indivíduos se conhecem relativamente bem. Procura-se evitar a estranheza mútua e contraria-se a indeterminação do outro. Tudo se exerce através da "conveniência", sem se cair numa exigência de total transparência. O esforço que é desenvolvido para neutralizar os perigos da transparência cria um modelo de espaço público em que se torna impossível suspender a aplicação das convenções colectivas. As relações inter-comunitárias são caracterizadas por um grau de permeabilidade das fronteiras entre os grupos que permite realizar um equilíbrio entre os contactos necessários e a indispensável preservação das minorias e das identidades. Trata-se de uma postura anti-assimilação e de defesa do multiculturalismo.

3) e 4) Corresponde à crise do espaço público na "sociedade intimista" actual, que põe em causa a existência de sociabilidade segundo as duas modalidades. Partindo da caracterização das formas de civilidade que estão presentes na sociedade de anonimato, o autor não apresenta em detalhe aquilo que se passa na sociedade de inter-conhecimento por considerar que aqui apenas se assiste a uma exacerbação dos fenómenos Desta forma quer na sociedade de anonimato, quer na sociedade de inter-conhecimento quando existe uma transparência nas relações sociais, verifica-se uma tendência para o desaparecimento das mediações simbólicas (ritos e rituais) que regulam as interacções sociais, pondo em causa a existência de espaço público. As relações inter-individuais são caracterizadas pela exigência de exibição da personalidade e de revelação da subjectividade na comunicação social. $O$ conteúdo da comunicação é feito de emoções, de dados biográficos, desaparecendo toda a distância e mediação impessoal. Verifica-se uma invasão progressiva da lógica do privado sobre o domínio público. Nas relações inter-comunitárias assiste-se à propensão de um grupo para exibir a sua personalidade colectiva, à afirmação arrogante da sua identidade comunitária e, consequentemente, ao desenvolvimento de comportamentos etnocêntricos e de auto-centramento. A ausência de mediação

Quadro $n^{\circ} 1$ - Tipologia Teórica de Espaços Públicos

\begin{tabular}{|l|l|l|}
\hline \multicolumn{1}{|c|}{ Sociedade } & \multicolumn{1}{c|}{ Anonimato } & \multicolumn{1}{c|}{ Interconhecimento } \\
\hline Troca & 1) Sociabilidade fria & 2) Sociabilidade quente \\
\hline Transparência & 3) Crise da Sociabilidade & 4) Crise da sociabilidade \\
\hline
\end{tabular}

Fonte: Lévy, 1997. 
simbólica entre grupos é substituída por uma ideologia da identidade e da autenticidade cultural que põe cada grupo a impor as suas particularidades e a negar todo o espaço público comum. $\mathrm{Na}$ sociedade de inter-conhecimento todas estas características são mais extremadas, correspondendo aos aspectos subjacentes à "sociedade tirânica", no sentido dado por Sennett, ou seja, assiste-se a uma constante conformidade ao grupo, a um controlo e vigilância generalizada.

B) A exploração do conceito de miscigenação à luz de três tipos de espaços públicos

No sentido de afinarem o conceito de miscigenação, um grupo de investigadores propôs a comparação de três espaços públicos - centro da cidade, bairro, grandes centros comerciais -, através da análise de um conjunto de dimensões: estatuto do espaço, morfologia (interior/exterior); acessibilidades (origem dos utilizadores, controlo de acesso, meios de transportes), miscigenação potencial, usos possíveis e tipos de actores em presença (Bassand et al., 2001). Os resultados obtidos nesta linha de pesquisa podem ser visualizados no quadro seguinte.
Baseando-se nestes resultados os autores põem em evidência o papel crucial e único dos espaços públicos do centro da cidade por comparação aos espaços comerciais das perferias. Realçam, assim, o facto dos efeitos da densidade humana não serem sinónimos de miscigenação social, e dos efeitos da acessibilidade diferenciada e dos usos possíveis não permitirem atribuir um estatuto às novas centralidades herdado das funções sociais do centro da cidade. Desta forma, vão explorar os tipos de miscigenação que coexistem nos espaços públicos centrais.

C) Espaços públicos do centro da cidade versus espaços públicos dos bairros desfavorecidos

Através de uma observação intensiva dos espaços públicos, da realização de entrevistas informais e semi-directivas para captar as representações sociais dos utilizadores, Pipard e Grané (2001) consideram que uma análise sistémica dos usos observados permite determinar o papel que cada uso exerce sobre o funcionamento global dos espaços públicos, dando-lhes sentido. $\mathrm{O}$ balanço de algumas pesquisas desenvolvidas em diferentes espaços públicos permitiu aos autores

Quadro $n^{\circ} 2$ - Tipologia Empírica de Espaços Públicos

\begin{tabular}{|c|c|c|c|}
\hline & Centro da Cidade & Bairro & $\begin{array}{c}\text { Espaços Comerciais das } \\
\text { Periferias }\end{array}$ \\
\hline Estatuto & Público & Público & Privado \\
\hline Morfologia & Exterior & Exterior & Interior \\
\hline $\begin{array}{l}\text { Acessibilidade } \\
\text { - Origem dos utilizadores } \\
\text { - Controlo de acesso } \\
\text { - Transportes }\end{array}$ & $\begin{array}{l}\text { Metrópole, cidade, } \\
\text { proximidade } \\
\text { Livre a todos } \\
\text { Acesso a toda a hora. } \\
\text { Bom acesso multimodal }\end{array}$ & $\begin{array}{l}\text { Proximidade } \\
\text { Livre a todos } \\
\text { Acesso a toda a hora. } \\
\text { Bom acesso peões }\end{array}$ & $\begin{array}{l}\text { Metrópole, cidade, } \\
\text { proximidade } \\
\text { Indesejáveis excluídos } \\
\text { Dias/horas encerramento } \\
\text { Bom acesso auto }\end{array}$ \\
\hline Miscigenação potencial & Origens múltiplas & Proximidade & Origens múltiplas \\
\hline Usos possíveis & $\begin{array}{l}\text { Circulação, cultura, } \\
\text { consumo diverso, } \\
\text { político }\end{array}$ & $\begin{array}{l}\text { Circulação, cultura, } \\
\text { consumo alimentar }\end{array}$ & $\begin{array}{l}\text { Consumo, alimentação, } \\
\text { cultura }\end{array}$ \\
\hline $\begin{array}{l}\text { Actores legítimos } \\
\text { Actores ilegítimos }\end{array}$ & $\begin{array}{l}\text { Cidadãos do centro do } \\
\text { município, comerciantes } \\
\text { Nenhum }\end{array}$ & $\begin{array}{l}\text { Habitantes do bairro, } \\
\text { comerciantes } \\
\text { Utilizadores não } \\
\text { habitantes do bairro }\end{array}$ & $\begin{array}{l}\text { Clientes e comerciantes } \\
\text { Excluídos em geral }\end{array}$ \\
\hline
\end{tabular}

Fonte: Bassand et al., 2001 
apresentarem os principais aspectos que caracterizam dois tipos de espaços. Centram-se, assim, na natureza das interacções sociais para estabelecer as principais diferenças das formas de apropriação entre os espaços públicos do centro da cidade e aqueles dos bairros mais desfavorecidos.

Referem que o espaço público do centro da cidade é o lugar do anonimato e das relações impessoais, as regras de sociabilidade não têm necessidade de ser aplicadas com rigor e existe uma certa tolerância face ao comportamento dos outros. Rompe-se o isolamento preservando-se o anonimato. Os usos tendem a estar ligados às actividades profissionais, aos lazeres e ao divertimento. É um espaço de uso ocasional e circunstanciado e o utilizador raramente é habitante, marcando, assim, uma relação muito específica com o espaço público e com os outros indivíduos.

Os autores reconhecem que existem diferenças entre os bairros mais desfavorecidos, sobretudo, por se verificarem variações de grau de convivialidade. Mas de uma forma genérica caracterizam o espaço público destes bairros por ser um espaço de proximidade, destinado ao uso "doméstico" e à sociabilidade de proximidade, e onde se é constrangido a ter em conta o outro. Cada um é objecto de um controlo social. A categorização opera-se de forma automática e natural. São lugares de difícil isolamento e de um anonimato comprometido. As sociabilidades tendem a traduzir os estigmas da precariedade e da pobreza, acentuando a segregação e a estigmatização dos bairros.

Embora na tipologia apresentada pela equipa coordenada por Bassand se faça referência aos espaços comerciais das periferias, todos os autores estão mais centrados na caracterização dos espaços públicos urbanos mais tradicionais. No entanto, a proliferação nas metrópoles daqueles novos espaços tem levado alguns autores, como Torres (2000), a questionar quais serão hoje os lugares da identidade colectiva? Que elementos constituem a identidade social contemporânea? Poder-se-á reconhecer uma identidade colectiva dos centros comerciais, ou seja, um conjunto de aspectos físicos que os tornam semelhantes entre si e ao mesmo tempo originais, diferentes de outros espaços e neste sentido potencialmente perceptíveis como lugares? Como caracterizar a urbanidade dos centros comerciais por comparação com outros tipos de espaços públicos "tradicionais"?

Não se pretende aqui dar resposta a todas estas interrogações, mas apenas lançar algumas pistas para posteriores aprofundamentos.

\section{Que Urbanidade para os Novos Espaços Públicos?}

Quando se olha para o espaço público como objecto de planeamento urbano coloca-se a questão do modelo de cidade convivial em que se baseia. Para Malcolm Miles (2001) este modelo é contraditório, pois o desenvolvimento da cidade é cada vez mais determinado por fluxos de capital trans-nacional em detrimento da satisfação de algumas das necessidades dos residentes. A tendência é, pois, para uma invasão ou substituição dos espaços públicos "tradicionais" pelo privado dos centros comerciais.

$\mathrm{Ph}$. Genestier questiona se os espaços públicos urbanos não estão a ser afectados por uma conformidade "às normas do mercantilismo turístico ocidental", uma vez que se assiste a uma "homogeneidade plástica" e a uma "redução das relações sociais que se estabelecem nos espaços públicos". Tendência ambivalente que, por um lado, toma em consideração a procura do cidadão contemporâneo para uma animação mais estimulante e, por outro lado, implica uma segregação acrescida (citado por Zepf, 2001: 68).

Dever-se-á, contudo ter presente que estes novos espaços públicos podem não traduzir de uma forma linear o estado da procura. $\mathrm{O}$ seu relativo "sucesso" parece ser um reflexo da oferta, ou seja, a intensificação da afluência aos novos espaços públicos traduzem a forma como a procura reagiu à oferta, uma oferta suficientemente atractiva ${ }^{7}$, mas mais imersa nos processos de mercado; de competitividade pela produção e comercialização;

\footnotetext{
Os produtores destes novos espaços procuram tornar a apropriação mais facilitada aos utilizadores, através de uma simulação que tende a recuperar uma parte do simbolismo e dos usos dos espaços públicos "tradicionais". É, assim, que no interior destes novos espaços os indivíduos se deparam com uma série de designações da morfologia urbana (praça, largo...), com mobiliário urbano e com decoração vegetal, aspectos estes inspirados, muitas vezes, em modelos importados que parecem contraditórios com a realidade de cada país, nomeadamente ao nível das condições climatéricas e das formas mais tradicionais de apropriação do espaço da rua, só para citar dois exemplos, mas que não deixam de apresentar uma série de vantagens aos seus utentes.
} 


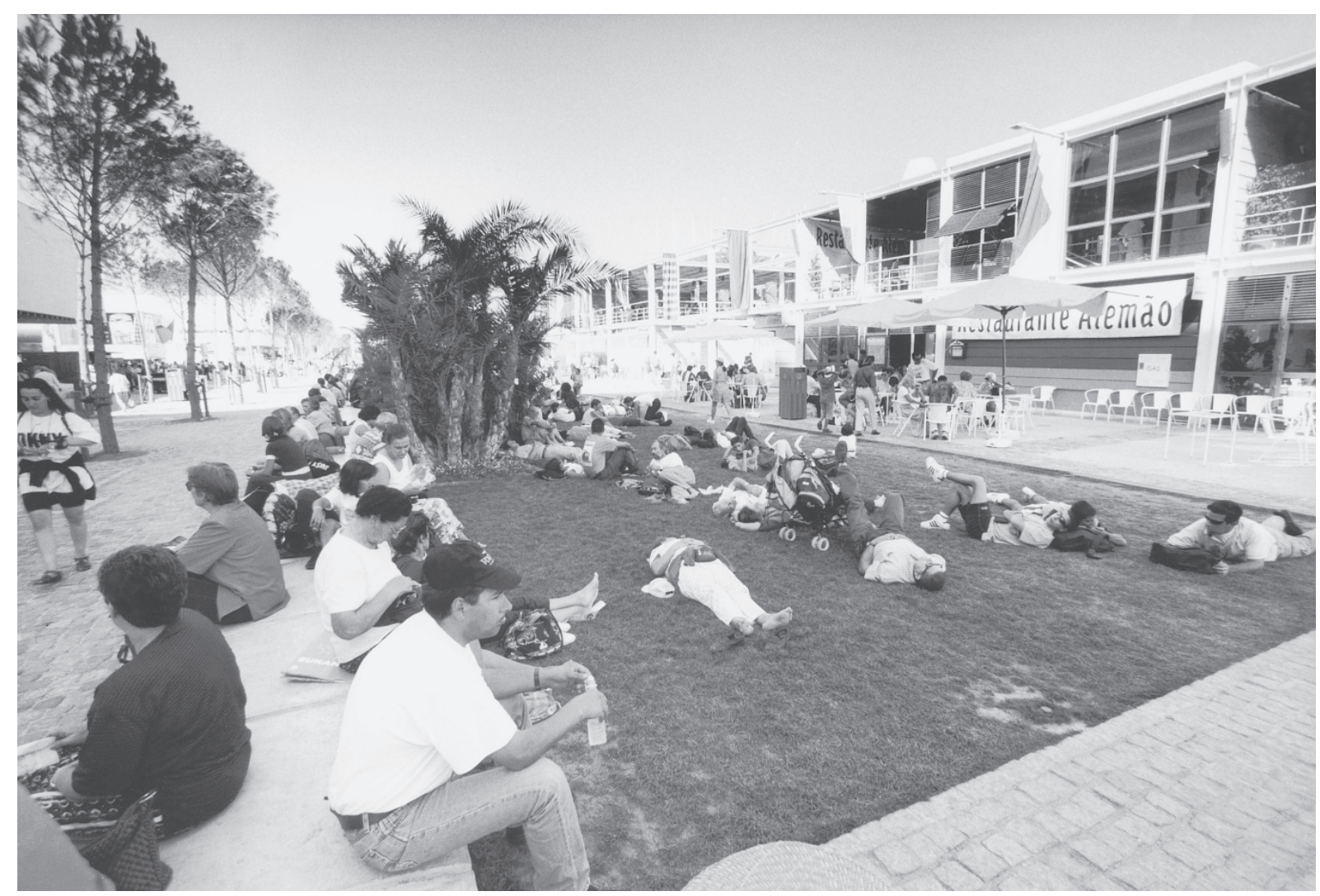

Foto de Miguel Baltazar, Expo'98.

de gestão da ocupação do tempo livre, no sentido de se gerarem lucros para a indústria de lazer.

Segundo Torres (2000), os espaços da identidade colectiva na cidade contemporânea tornam-se aqueles onde se provam e experimentam as emoções e as identificações colectivas frágeis ligadas à distracção, aos divertimentos, ao consumo e à estética. No entanto, os novos espaços públicos constituem ambientes com formas de sociabilidade provisórias e com processos de construção da identidade colectiva em torno de símbolos efémeros da cultura de consumo. Não são tanto indivíduos, mas "tribos" ou grupos sociais já constituídos (famílias, grupos de jovens, casais) que afluem a áreas vastíssimas e segundo temporalidades fragmentadas. Estes espaços são interpretados como espaços "tribais", pós-individualistas, baseados mais no "contacto", do que no "contrato". O consumidor e o turista percepcionam simbólica e esteticamente ambientes físicos e sociais espectaculares, que contrastam fortemente com os lugares mais tradicionais, pobres em conteúdo comunicativo.
Se o uso dos espaços públicos mais tradicionais não correspondem aos modos de vida urbanos mais recentes e a práticas de sociabilidade muito marcadas pela festivalidade e se estes novos espaços, na maioria das vezes de natureza privada, apresentam condições atractivas e respondem àquelas novas formas de estar em público, então, torna-se necessário, como alerta Ascher que os profissionais do espaço dêem uma atenção particular a estes "lugares metapolitanos" ", já que “(...) são estes lugares que é preciso adaptar e qualificar" (Ascher, 1998: 177). Isto porque se continua, ainda, a conceber uma "cascata hieráquica de espaços e de equipamentos que já não correspondem às práticas da maioria da população (...) os arquitectos e os urbanistas continuam a reservar-lhes [às relações sociais de proximidade] uma importância desmesurada, reproduzindo imagens comunitárias cada vez mais afastadas das sociabilidades urbanas, concebendo microespaços públicos ingeríveis, reservando lugares de comércio que nunca virão, produzindo ruas que permanecerão deseperadamente simples

\footnotetext{
${ }^{8}$ Nomeadamente aos centros comerciais integrados, aos parques, aos grandes equipamentos de lazer, aos "centros" de negócios, às “zonas" de actividades, aos "pólos" científicos e técnicos.
} 
vias de acesso aos estacionamentos dos prédios (...) tentando enfim reencontrar a urbe clássica ou medieval por incapacidade de produzir uma sociedade contemporânea" (Ascher, 1998: 176).

Para Marcus Zepf (2001), a procura de novos referenciais urbanos para conceber os espaços públicos implica uma análise aprofundada dos processos de utilização, de produção e de formação destes espaços. Em primeiro lugar, trata-se de compreender como i) se constituem as representações e as concepções dos "produtores" (profissionais do espaço e políticos); ii) se organizam as práticas sociais dos utilizadores (residentes, cidadãos e visitantes); iii) se formalizam os parâmetros espaciais (aspectos geográficos, características arquitectónicas, composição do mobiliário urbano). Em segundo lugar, trata-se de exprimir certos fenómenos contemporâneos que contribuem a sublinhar determinadas realidades socioespaciais e permitem uma melhor definição da noção de urbanidade, nomeadamente a teatralização, festivalização e comercialização dos espaços públicos. O ênfase que é dado a estes aspectos parece fazer todo o sentido quando se complexifica a procura de espaços públicos, sobretudo, traduzida por uma necessidade de lugares com finalidades muito definidas, mas, simultaneamente, polivalentes e abertos a usos imprevistos.

Este autor sistematiza as principais dimensões da urbanidade (social, socioespacial e político-administrativa), considerando que o princípio que lhe subjaz reside, sobretudo, numa lógica paradoxal que procura conciliar elementos opostos de cada uma das dimensões da urbanidade. Desta forma, a dimensão social contrapondo esfera pública/esfera privada; densidade/diversidade; segurança/animação; conflito/tolerância, apresenta um conjunto de factores de urbanidade social, tais como:

- a heterogeneidade e a densidade dos grupos sociais;

- a emergência de um sentimento de segurança fundado num tipo de controlo social informal;

- a dialéctica entre esfera privada e esfera pública, fazendo aparecer códigos de comportamentos que favorecem o reencontro e a comunicação;

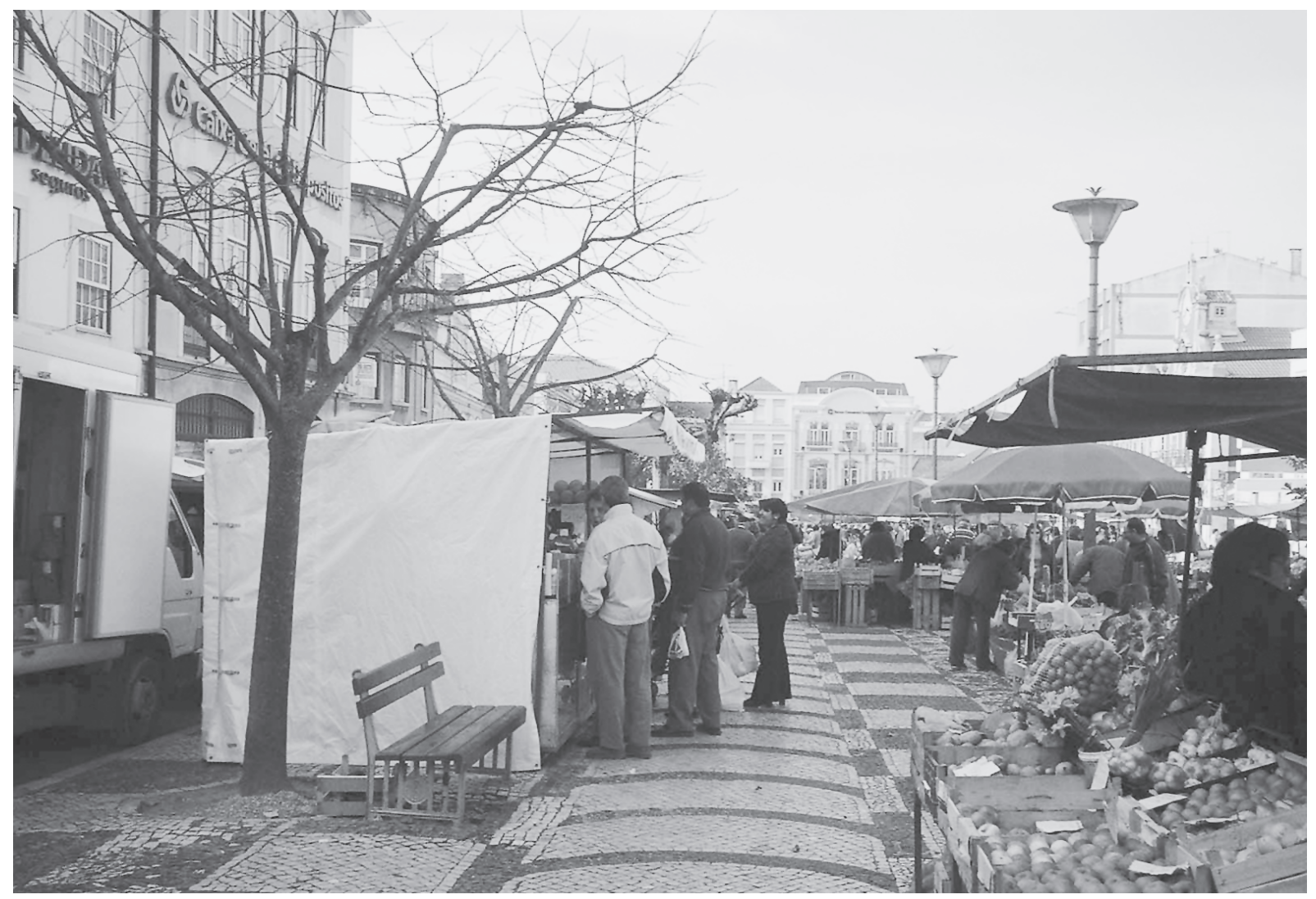

Foto de Vasco Baltazar, Caldas da Rainha. 
- os conflitos de uso e de estatuto que marcam a emancipação do indivíduo face ao controlo social.

A dimensão socioespacial opondo limites espaciais/disponibilidade de terrenos; arquitectura coerente/sentimento de espaço (cheio/vazio); carácter vegetal/carácter mineral, aponta, igualmente, para um grupo de condições de urbanidade espacial:

- a leitura da estrutura urbana ao nível das unidades que constituem as malhas do tecido urbano;

- a capacidade de perceber a dialéctica entre os espaços construídos e os espaços vazios.

Por último, a dimensão político-administrativa tem em consideração as oposições funcionalidade potencial/funcionalidade real; entidade urbana/ descontinuidades urbanas; lógica de permanência/ lógica de passagem; ordem/desordem. Esta dimensão assinala um atributo fundamental da urbanidade político-administrativa que consiste no desafio que se coloca ao planeamento e à gestão da urbanidade na avaliação das realidades que determinado espaço urbano apresenta, nomeadamente através de uma análise estratégica que equaciona as suas forças, fraquezas, oportunidades e ameaças.

Este autor parece ter uma visão mais optimista das formas de sociabilidade que se podem desenvolver nos novos espaços públicos, independentemente da sua natureza jurídica. É o caso, por exemplo, do reconhecimento dos elementos que se opõem na dimensão social da urbanidade, sem que essa oposição se tenha de traduzir numa crise de civilidade e no questionamento da existência de espaços públicos. Apresenta-se, em contrapartida, um conjunto de factores que tendem a favorecer a urbanidade, e mesmo que não sejam exaustivos deixa-se aqui um desafio para se aprofundar a compreensão quer do significado social e cultural dos novos espaços públicos, quer da polarização que se assiste entre espaços de cultura global do espectáculo e consumo e espaços locais de abandono e pobreza. 


\section{Referências Bibliográficas}

AUGÉ, Marc, 1994, Não-lugares. Introdução a uma antropologia da modernidade, Venda Nova, Bertrand, 1992.

ASCHER, François,1998, Metapólis. Acerca do futura da cidade, Oeiras, Celta, 1995.

BASSAND, et al., 2001, Vivre et créer l'espace public, Lausanne, Presses Polytechniques et Universitaires Romandes.

BORJA, Jordi, 2000,"Fazer cidade na cidade actual. Centros e espaços públicos como oportunidades" in BRANDÃO, P.; REMESAR, A. (coord.) Espaço Público e Interdisciplinaridade, Lisboa, Centro Português do Design.

CAPRON, Guénola, 1998, "Les centres commerciaux à Buenos Aires. Les nouveaux espaces publics de la ville de la fin du Xe siècle", Les Annales de la Recherche Urbaine N. ${ }^{\circ} 78$, Paris, Ministère de L'Équipement, des Transports et du Tourisme.

CASTRO, Alexandra et al., 2001, "Os ciganos vistos pelos outros. Coexistência inter-étnica em espaços urbanos", Cidades. Comunidades e Territórios, 2, Lisboa, CET/ISCTE, pp. 73-84.

GOTMAN, Anne, 2001, Le Sens de l'hospitalité. Essai sur les fondements sociaux de l'accueil de l'autre, Paris, PUF.

GRAFF, Philippe,1996, "Approche analytique de l'espace public urbain contemporain" in L'Espace Public dans la Ville Méditerraneenne, vol. 2.

JOSEPH, Isaac, 1991, "Voir, Exposer, Observer" in L'espace du public, les compétences du citadin, Colloque d'Arc-et-Senans, nov-1990, Plan Urbain-Éditions Recherches.

JOSEPH, Isaac, 1998, La ville sans qualités, Paris, Editions de l'Aube,

LE BRAS, Hervé, 1997, Ville et hospitalité, Textos de síntese do Seminário, Paris, Fondation Maison dês Sciences de l'Homme, Plan Construction et Architecture.

LEVY, Albert, 1996, «L'espace public de la ville méditerranéenne: mythe et réalité » in L' espace public dans la ville méditerranéenne, Actes du colloque de Montpellier, mars 1996, Saint-Estève, Ed. Esperou.

LEVY, Albert, 1997, Explorer l'espace public, Laboratoire Theorie des Mutations Urbaines en Pays Developpes, Institut Français d'Urbanisme, Marne-La-Vallée, Texto policopiado.

MATIAS FERREIRA et al., 1997, Lisboa, a Metrópole e o Rio, Lisboa, Bizâncio.

MATIAS FERREIRA, Vítor, 2000, "Cidade e Democracia. Ambiente, Património e Espaço Público", Cidades. Comunidades e Territórios, l, Lisboa, CET/ISCTE, pp. 9-35.
MATIAS FERREIRA, Vítor; CASTRO, Alexandra, 2000, "Espaços públicos e verde urbano em Lisboa. Um estudo de caso sobre ambiente urbano", Cidades. Comunidades e Territórios, 1, Lisboa, CET/ISCTE, pp. 85-100.

MATIAS FERREIRA, Vítor, 2001, "Protagonismo urbano e projecto de cidade". A condição pública e patrimonial das cidades", Cidades. Comunidades e Territórios, 1, Lisboa, CET/ISCTE, pp. 33-45.

MAYOL, P., 1980, L'invention du quotidien II - Habiter, Paris, UGE.

MILES, Malcolm (2000) "Depois do domínio público: espaços de representação, transição e pluralidade" in BRANDÃO, P.; REMESAR, A. (coord.) Espaço Público e interdisciplinaridade, Lisboa, Centro Português do Design.

MILES, Malcolm (2001) Para além do espaço público, Lisboa, Associação Extra-Muros e Centro Português do Design.

PINÇON, Michel (1981) Cohabiter groupes sociaux et modes de vie dans une cité HLM, Paris, Plan Construction.

PIPARD, O.; GRANÉ, Jean (2001) «L'expérience de l'observation en bureau d'études» in TOUSSAINT, Jean-Yves; ZIMMERMANN, Monique, User, observer, programmer et fabriquer l'espace public, Laussanne, Presses Polytechniques et Universitaires Romandes.

QUÉRÉ, Loius (1992) «L'espace public: de la theorie politique à la meta-theorie sociologique», Quaderni, 18.

RÉMY, Jean; VOYÉ, Liliane (1981) Ville, ordre et violence, Paris, PUF.

SENNETT, Richard (1979), Les tyrannies de l'intimité, Paris, Seuil.

TORRES, Marco (2000) Luoghi magnetici. Spazi pubblici nella città moderna e contemporanea, Milão, Franco Angeli.

TOUSSAINT, Jean-Yves; ZIMMERMANN, Monique, «L'espace public en débat» in User, observer, programmer et fabriquer l'espace public, Laussanne, Presses Polytechniques et Universitaires Romandes, 2001.

VOLLE, Jean-Paul (1996) «Questions à l'espace public, l'espace public en question» in L'espace public dans la ville méditerranéenne, Actes du colloque de Montpellier, mars 1996, Saint-Estève, Ed. Esperou.

ZEPF, Marcus (2001) «Les paradigmes de l'espace public» in TOUSSAINT, Jean-Yves; ZIMMERMANN, Monique, (org.) User, observer, programmer et fabriquer l'espace public, Laussanne, Presses Polytechniques et Universitaires Romandes.

ZEPF, Marcus (200la) «Connaissance et traduction du paradoxe urbain» in TOUSSAINT, Jean-Yves; ZIMMERMANN, Monique, (org.) User, observer, programmer et fabriquer l'espace public, Laussanne, Presses Polytechniques et Universitaires Romandes. 